\title{
Competitiveness of students in the culture sphere in the modern educational space
}

\author{
Nataliya Novikova ${ }^{1, *}$ \\ ${ }^{1}$ Moscow Technological Institute, 199334, Moscow, Russia
}

\begin{abstract}
The real educational system must be modified because of global changing in social life. It is necessary to use the innovative technologies in the educational process. The modern labour market takes the special claiming to the graduates. It is important to study the competitiveness of students in the culture sphere. Thus, the article is devoted to the study of the competitiveness of students studying in educational institutions in the culture and art spheres; problems of modern information technologies introduction in educational process of such educational institutions.
\end{abstract}

\section{Introduction}

Modern society is significantly influenced by the process of globalization, characterized by the emergence of a multicultural sphere, dynamically transforming cross communicative processes, by mixing of international and national traditions and their tendency to a qualitatively new transformation and reinterpretation, strengthening the role of innovative information technologies in human life. The main potential of the development and functioning of these processes is incorporated in the educational environment, which plays a key role in the modernization of society. This paradox is education closeness, poor involvement in information and communication transformation of the modern world [1]. Being the important component of social reality, information technologies have a serious impact on all spheres of public life, shaping other's attitudes, personality value orientations and presenting new requirements to its competitiveness. Economic system destabilization, recurrent political crises, rapidly occurring transformation in the cultural and social life of Russian society on the one hand and the strengthening of transnational corporations role, active migration processes, rapid growth of innovative technologies, striving to the formation of a single economic space on the other hand, show some level of inconsistency of existent globalization processes, that, in turn, places high demands on an individual as a competitive subject of global labour market [2]. Having a multi-level character, this is the labour that serves as a fundamental basis of competitiveness, which can be considered as one of the key indicators of social production efficiency and a system forming factor of a level of society and the state development. Thus, in the postindustrial, information society is the driving force of the economy becomes an intellectual capital, creative, able to work in a multitasking competitive mode personality, with the necessary potential to achieve benefits in stratified and permeated by globalization processes continuously transforming society conditions. The formation of such identity involves a change in state policy in the education system, the revision of existing attitudes on social partnership in this sphere, development of innovative institutional mechanisms aimed at closer cooperation and the creation of a coherent system of mutually beneficial interaction between the labor market and education [3].

\section{Analysis and discussion}

Graduates nowadays are a poorly protected and prepared social group experiencing significant difficulties in the process of professional self-determination, and in the process of further employment and creating a career. Their spontaneous, often uncontrollable adaptation to the labour market leads to the loss of the young generation moral values, the disintegration of the emerging image of the world, immaturity of life strategies and attitudes, and as a result to a rapid moral and professional burnout and the loss of theirselves as a competitive unit in a professional environment [4]. In this regard, it is education that becomes the leading factor of formation and development of the competitiveness of the society productive forces, giving the opportunity to judge the presence of individual competitive advantages and further forming his effective employment. The dominant role of education in this process was proven by $\mathrm{G}$. Becker and T. Schultz, the founders of the human capital theory. Despite the existence of some, to a certain extent, complementary approaches to this issue, in general, the problems of graduates competitiveness on the labour market remain to date not fully developed, especially for graduates undergoing training on creative directions,

Corresponding author: $\underline{\text { n novikova@,mti.edu.ru }}$ 
having their own special specifics often not fully taken into account. In particular, it relates to the justification of institutional interaction mechanisms between different labor market and education subjects, the functioning of which, to date remains fragmented and not consistent especially for educational institutions of a creative focus.

I would like to elaborate on such direction of educational activity in the sphere of culture as choreographic art. The system of choreographic education in Russia demonstrates a consistently high level of training. However, in this area there are processes of decentralization due to the transformation of the socio-cultural world. The necessity of society in a new type of competitive specialist require reform of choreographic education, the upgrading of which must be built with historical traditions and taking into account the current innovative methods and forms of upbringing of a new type. From this point of view constructing of a new model of choreographic education that meets the modern trends and functioning in the post-industrial society, contributes to its organic inclusion in the context of globalization and its popularization in modern society. Multicultural environment raises the necessity for close cooperation of domestic and foreign choreographic education system. Such acculturation on the one hand, has the risk of loss of national identity, the uniqueness of Russian education in this sphere, taking the graduates to an existing template, on the other - contributes to the enrichment of the educational experience, the appearance of new forms and methods of implementation of the educational process. Intercultural interaction, as an inevitable consequence of globalization will accelerate the process of education modernization in the creative sphere, accumulating the existing historically established national traditions and innovative socio-cultural changes. Cultural diffusion in the educational system will help to shape the identity of a new type, resistant to dynamically changing conditions in society and focused on career growth and professional development.

The main problems of educational institutions of culture sphere, in particular choreographic sphere, can be attributed to the existing conflict between the social necessity of preparing young generation for professional and socio-cultural activities in the new socio-economic environment on the one hand and the limited capabilities of educational institutions to provide such training that meets the innovation processes taking place in society. The solution to this problem actually lies in the determining the correspondence of objectives, contents, values, mechanisms of the educational institutions functioning with new social and economic conditions in solving educational problems. The search of this compliance entails the transformation of the educational process -its saturation with the modern ways and methods of lessons constructing, the introduction of a greater number of information resources, modifying the structural and functional characteristics of the educational process in general [5]. As for educational institutions in the culture sphere, for a long time they functioned quite independently, while remaining closed to innovative trends, inaccessible for the average man, focused on fundamentally different socio-cultural and economic conditions. However, the existing life realities lead to the necessity to implement major structural changes: to expand the range of specialties in vocational schools and training programs in higher education; the use of foreign experience; establishing partnerships with foreign counterparts; a gradual withdrawal from the "elitism" of such education, the creation of a unified information and communication space with employers and educational institutions of different levels; active introduction of information technologies.

It should be noted that the successful employment of graduates with the ability to compete in the international labor market currently is not absolute. Among the dominant reasons for this situation are 1) a clear social institutions of education and employment separation of functions, 2) a lack of established partnerships of educational institutions with potential jobs, 3) the orientation content of training and educational programs on outdated professional requirements, 4) little implementation of information technologies. All this shows the urgent need of building a system of social institutions of education and employment more dense cooperation, based on a synthesis of traditional and innovative educational technologies. The system of graduates' employment in the sphere of culture should be more deeply integrated into the external environment, occupying a specific segment of the labour market through well-developed regulatory framework, considering both the existing professional educational standards and the employers' expectations. In addition, the educational process must be adjusted in accordance with the employer's requirements, the needs of society and students as the subject of employment. As for choreographic education, there are cases of significant differences of existing requirements for graduates in the labour market and educational programs acting within schools, modern realities and new educational and professional trends not taking into account in the proper amount. Among the main problems in the implementation of the educational process within the framework of education in the field of culture can be described as follows: isolation, formal practices, insufficient use of international experience and information technologies weak involvement in the educational process. Practice should not only be considered as an integral part of the educational process aimed at the testing of formed abilities and skills, but also as an important form of psychological and professional adaptation, which will subsequently allow a graduate painlessly and with minimal emotional losses to enter into workers' association endowed with special contradictions and specifics in the arts field, sometimes complicating the process of occupational adaptation.

The formation of a competitive personality is possible only under condition of the graduates' employment system integration into the system of management by educational institution. The development of a competitive specialist in the field of culture and art should be complex, affecting several levels: 1) a personality professional orientation 2) professional identity, promoting personality awareness 
of itself in the arts sphere, 3) professional competences, enabling to develop skills and implement successful employment, 4) social and personal development of a graduate, his commitment to multitasking, openness to new trends, 5) psychological competence, focused on the self-realization pursuit, self-development, the maximum utilization of his capacity and potential [6]. The development of a graduate's competitive advantages largely depends not only on the quality of professional education, but also on personal development, the formation of his active, adequate, and mobile behavior in the labor market.

It should be noted that personal characteristics of the graduates of creative disciplines, such as the strength and activity of personality, ability to reflection, the level of personal and professional standards, the need for creative self-actualization, creativity and character capacities, etc. have certain features largely depending on their professional and social status. The specifics of their activities does not appear to be only the formal compliance with the rules and canons, as it leads to low productivity of creative work and lack of competitive advantages development. Highly productive and competitive is a creative work that focuses on selfeducation, self-development, and the pursuit of new forms and methods of expression accumulation. During the formation process of students' individual psychological characteristics on a specialty "Choreographic Art" , the disclosure of their creative potential, identifying competitive advantages comes. The creative work of students of the arts educational institutions is a co-creation with the teachers. In this regard, the teachers professional skills, the ability to take creative solutions to enrich the learning process with expressive means and modern educational techniques, plays a key role. Thus, the conditions of creative work productive development can be defined as the interactions optimizing of students, teachers and employers in the process of co-creation, the development of psychological competence, which makes it possible to build a strategy for personal and professional development of the reproductive level to competitive modeled.

It should be noted that in today's realities the use of innovation, in particular, information technologies in the educational process is of a great importance for competitive formation. However, this practice has not yet been mastered in full in the sphere of culture. Traditionally, in the choreographic art, the information from the teacher to the student was passed by the demonstration means. For practicing and consolidating the skill of performance of any movement a student must repeatedly perform this movement, i.e., as closely as possible to meet all the guidelines and comments of the teacher. However, the explanation of the nuances of this or that movement execution cannot be solely in a descriptive form. That is why modern information technology visual presentation of teaching material is particularly important in the study of choreographic disciplines. Progressive development of various multimedia resources, virtual platforms has made it possible to introduce the most modern educational trends in this field, experience exchange with other educational institutions, the use of master-classes of leading masters and highly qualified specialists in this area, that undoubtedly has a beneficial influence on the development of professional preferences and skills, significantly expanding students horizons and their common orientation in the professional world. Information technologies make it possible to see rapidly appearing new choreographic styles, experimental approaches, embodying a synthesis of choreographic dance schools. Non-traditional forms of choreographic education widely use information technologies as the basis for teaching materials creation, to minimize time and human costs in the implementation of the educational process. Working with multimedia materials, introducing the students the classical choreographic heritage, is an integral part of the theoretical teaching of special subjects in choreographic schools. The use of educational methodical multimedia materials in learning practical major disciplines, however, every year is becoming increasingly important for the formation of a competitive specialist. Reference display of studied movements contributes to the formation of students' professional competences, the creation of new expressive forms, the development of broad general professional views about their chosen profession. Electronic courses development in a single e-learning platform on theoretical and practical special disciplines will open the access to the best examples of the choreographic art, to rehearsal files that will allow getting advice from the teachers in time; to choose the most advantageous performance variant, to identify any errors and inaccuracies in the choreographic material transmission. Another way of using information technologies in the field of choreographic education is themed websites representing comprehensive multipurpose resources which include: literature, teaching materials, articles on choreographic art and creativity; videos of the best choreographic works; music and music materials. Turning to such resources expands the students' horizons, forms the general cultural competence, and contributes to the formation of professional identity. It should be noted that the use of modern information technologies within learning the choreographic creativity has a number of specific differences and is currently at the stage of formation. Existing training Internet resources, discussion boards, electronic platform that combines several educational institutions in this sphere, will continue to develop and work on several fronts - general cultural development and professional training through the organization of thematic or master class. Such forms of distant learning like video tutorials, webinars, and interactive modules on subjects will also be gradually adopted in practice of educational activity. The implementation of information technologies complements the traditional form of management of the educational process with the aim of improving graduates' professional skills and competitiveness. 


\section{Conclusions}

Thus, for the formation of a competitive graduate of creative orientation educational institutions, to the foreground comes the need to create internal capacity of upgrading educational institutions, the use of relevant, meeting modern requirements theoretical and methodological models, the use of social mechanisms of formation and transmission of educational activities norms and meanings that meet the society postindustrial requirements, the transformation of targets, values of the students, the early development of professional consciousness and the widespread introduction of modern information technologies that enable to fully develop the necessary competencies for a competitive fight. It should be noted that the construction of a new education model will not only contribute to the improvement of specialists' competitiveness and the promotion of creative education, to solving educational problems, consolidating the modern Russian society.

\section{References}

1. N.A. Zima, Fundamental research. 7, 78-80 (2006)

2. S.D. Reznik, A.A. Sochilova University management. 3, 70-77 (2010)

3. V.G. Semeko, Education economy, 6, 39-45 (2010)

4. N.N. Fedotova, Philosophical Sciences, 4, 5-24 (2010)

5. T.A. Filanovskaya, The philosophy of Education, 2, 195-203 (2011)

6. T.A. Filanovskaya, Higher education in Russia, 2, 144-149 (2010) 